
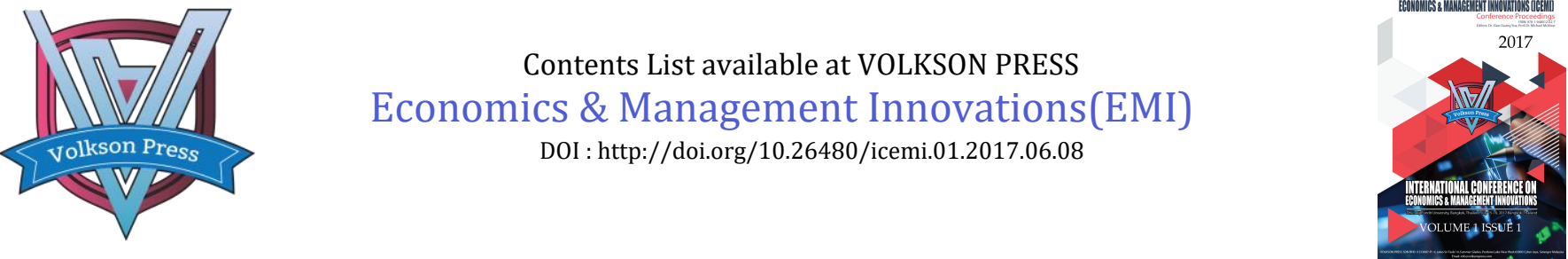

\title{
Study on the Innovative Talents Training Mode of College Students Based on VBSE Training Platform- - A Case Study of Wuhan Donghu University
}

\author{
Qiong-jie ZHOU ${ }^{1,{ }^{*}}$,Tong-tong ZHENG ${ }^{1, a}$ and Fei CHEN ${ }^{1}$ \\ ${ }^{1}$ Wuhan Donghu University,301wenhua Road, jiangxia District, Wuhan,430212,Hubei,China \\ aCorresponding author *email: katharine7878@163.com \\ This is an open access article distributed under the Creative Commons Attribution License, which permits unrestricted use, distribution, and reproduction in any \\ medium, provided the original work is properly cited.
}

\section{ARTICLE DETAILS}

\section{Article History:}

Received 02 october 2017

Accepted 06 october 2017

Available online 11 october 2017

Keywords:

VBSE;Talent training;Innovation and entrepreneurship;College

students; Data

\section{ABSTRACT}

Through the investigation of the employment situation of contemporary college students to Wuhan Donghu University nearly two graduates as a example,"whether to use VBSE training platform" and "the training platform is conducive to innovation and entrepreneurship" as the data basis, to understand the difference of college students' employment situation on the basis of this platform.This paper will start from the innovative talent strategy, combined with the characteristics of VBSE system itself, combined with a series of data comparison analysis, and explored the VBSE training platform whether the promotion of personnel training for college students.

\section{Introduction}

In April, 2016, at the Fifth Plenary Session of the 18th CPC National Congress, General Secretary Xi Jinping once again stressed: "while adhering to innovation and development, it is necessary to focus on innovation in the overall development of the country, and people are key factors in technological innovation". In this era of knowledge economy, innovation and personnel training ability have become important factors measuring comprehensive national strength. Based on the practice of China, in today's society, although many students have grasped enough basic knowledge, they have unrealistic fantasies about social positions, have great ambition for salary and position but little talent and lack innovation ability in work

Under this background, China's major colleges and universities have carried out a series of curriculum reform, such as carrying out innovation and entrepreneurship competition, establishing two-mentor entrepreneurial counseling mechanism, establishing specialized personnel training incubator base and so on. Based on the analysis and research on virtual business social environment (VBSE) training platform, and combined with the case study of Wuhan Donghu University, this paper discusses whether applying the teaching mode of "ordinary classroom + VBSE" in college curriculum reform is more conducive to the development of student employment.

\section{VBSE Training Platform}

Virtual Business Social Environment (VBSE) is an "integrated simulation training platform of virtual business social environment" designed and developed by UFIDA New Technology Co., Ltd., internal: setting prevalent departments and corresponding positions in the enterprise through the extraction and combination of the typical characteristics of various organization forms in modern enterprises. VBSE hopes to create a virtual business social environment by extracting the typical features of different morphological organizations, so that the trainees can connect business simulation with real work, conduct simulation operation and business operation and conduct macro-micro management and multi-person collaborative simulation business in the virtual market environment, business environment, government environment and public service environment, according to the work content of actual position, the business process and the business documents. It is a training product satisfying multi-professional learning and practice.

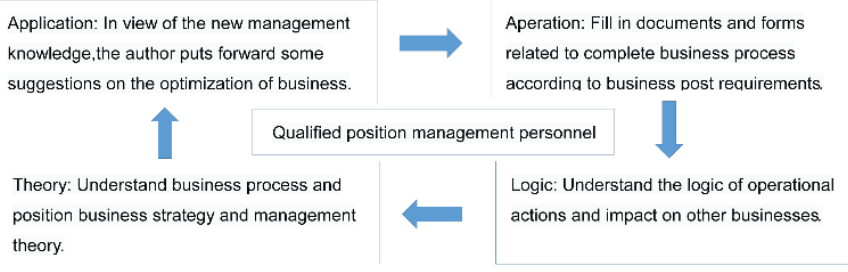

Figure 2-1 VBSE Training Platform Introduction

\section{Data Analysis - A Case Study of Wuhan Donghu University}

\subsection{Survey Background Introduction}

The survey focuses on economics and management related disciplines of Wuhan Donghu University. And "whether to participate in VBSE course" and "whether VBSE course is helpful for employment" are the dependent variables of the survey. There are a total of 18 questions in the questionnaire, 11 questions of which are common questions based on option logic, and 3 questions of which are step-to-step questions.

The survey subjects are mainly juniors and seniors, and a small part of freshmen and sophomores. The purpose of surveying this type of students is: First, juniors and seniors are facing graduation, and they hold their own opinions on social practice; Secondly, compared to juniors who have fully experienced VBSE training course, only partial 2017th graduates are selected in the trial of the initial construction part of VBSE course, and most of the 2017th graduates have not received VNSE education, so that whether school training course is beneficial for practical work can be found through the comparison; Finally, juniors and seniors have received a relatively complete, systematic education and training in school and have corresponding feeling and experience for the overall education and teaching system, so that students' views for the personnel training of the school can be better reflected. The questionnaires are collected through the mode of online e-questionnaire, 103 copies of complete questionnaires 
are collected, and there are 100 valid questionnaires and 3 invalid questionnaires.

\subsection{Statistical Results Analysis}

\subsubsection{Cross-analysis on Statistical Data}

(1) Conducting cross-analysis by using grade as an independent variable: college students have practical consciousness.

As is shown in Table 3-1, grade is the independent variable. As the survey subjects are mainly juniors and seniors, it can be found through the survey analysis that $96.88 \%$ seniors who already have relative work experience basically agree to conducting practical course in college, which is consistent with "innovative talent training scheme should strengthen students' practical experience" in the background survey.

Through in-depth cross-analysis, we believe that many students has been aware of the importance of practice in the learning stage, hoping to better combine theoretical knowledge with practice, but due to restrictions like time, place and learning courses, they cannot establish a good connection with the community (Figure 3-1). Only 35\% freshmen, sophomores and seniors take part in practical work. The current problem is that students are willing to participate in practical courses, and especially for students of applied universities, how to save time and effort and take into account both theoretical courses and practical operation is the main problem.

\section{Table 3-1 Proportion of Survey Population Participating in Work}

\begin{tabular}{|c|c|c|c|c|}
\hline Grade & $\begin{array}{c}\text { The class of } \\
\text { 2016(Fresh } \\
\text { man) }\end{array}$ & $\begin{array}{c}\text { The class of } \\
\text { 2015(Sopho } \\
\text { more) }\end{array}$ & $\begin{array}{c}\text { The class } \\
\text { of } \\
2014(J u n \\
\text { ior) }\end{array}$ & $\begin{array}{c}\text { The class } \\
\text { of } \\
2013(\text { Sen } \\
\text { ior) }\end{array}$ \\
\hline $\begin{array}{l}\text { Participa } \\
\text { tion rate }\end{array}$ & Zero percent & $\begin{array}{c}\text { Seven } \\
\text { percent }\end{array}$ & $\begin{array}{c}\text { Twenty- } \\
\text { eight } \\
\text { percent }\end{array}$ & $\begin{array}{c}\text { Sixty-five } \\
\text { percent }\end{array}$ \\
\hline
\end{tabular}

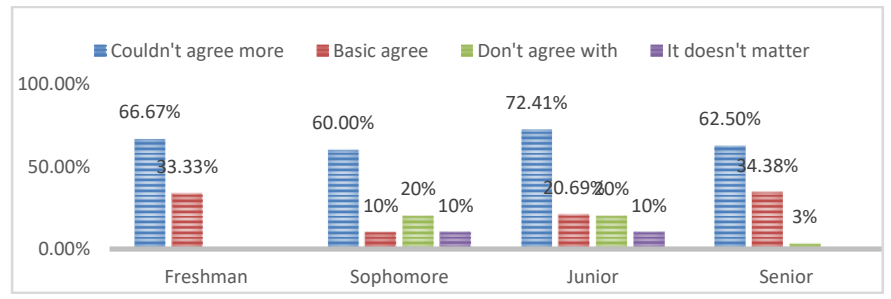

\section{Figure 3-1 Whether Practical Course Survey Is Needed in College}

(2) Conducting cross-analysis by using whether to participate in work as an independent variable: VBSE courses help students strengthen practical ability.

Whether to participate in the work is used as an independent variable to see if VBSE courses are helpful for study or work. As is shown in Figure 3$2,23.53 \%$ of the students who are studying the VBSE program and $15.94 \%$ of the students who are already working consider VBSE courses are helpful in their work. The author then investigates their opinions on the enterprises' requirements for college students employment through multiple choice questions, and finds that college students generally think that "comprehensive quality" and "practical experience" account for more than $90 \%$, and college students generally believe that modern enterprises propose higher requirements for employees in the aspects of comprehensive quality and practical ability. As is shown in Figure 3-3, in terms of practical experience, VBSE courses enable students to understand the operation of the company through the operation simulation of the enterprises, and students can directly carry out the simulation practice of company operation in the school without the limitation of the environment, saving time and energy. Practice education is conducted on college students through a series of practical modules, so that students can adapt to social work experience in advance.

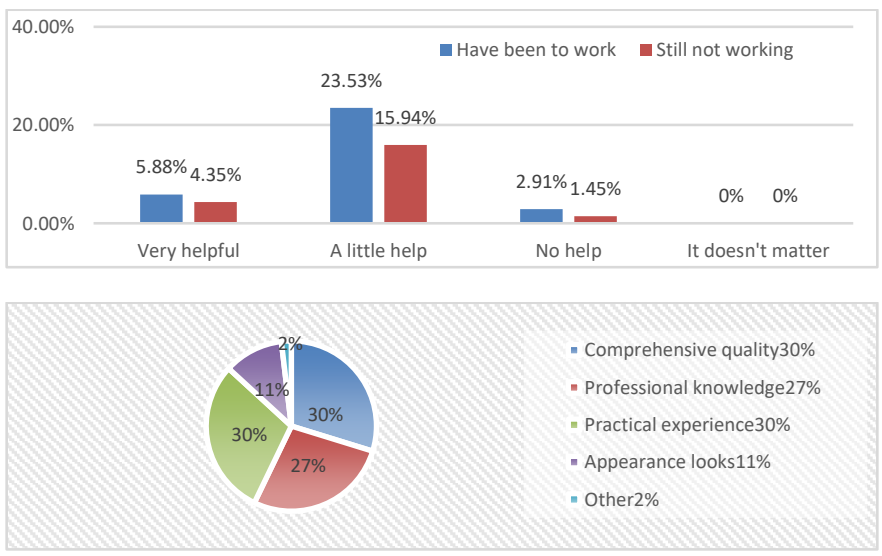

Figure 3-3 Social Requirements for College Students

(3) Conducting cross-analysis by using part-time job experience as an independent variable: unnecessary part-time job occupies energy.

Whether participating in any part-time jobs is used as an independent variable to conduct relative analysis on its relation with "innovation and entrepreneurship" competition in the school and students' own career planning. We conclude that students who have part-time job experience outside the school are less engaged in "innovation and entrepreneurship" competition, and that most students do not have a clear career plan.

Figure 3-4 shows: in their career planning, 18\% of them clearly do not have part-time job experience, and $45 \%$ of those who have part-time job experience do not have clear career planning. Although the total population having no part-time job experience is less than the total number of those having part-time job experience in the survey, it can be seen from Figure 3-5 that only one student has part-time job experience and has participated in the Innovation Entrepreneurship Competition, and three students have no part-time job experience but have participated in competitions for many times.

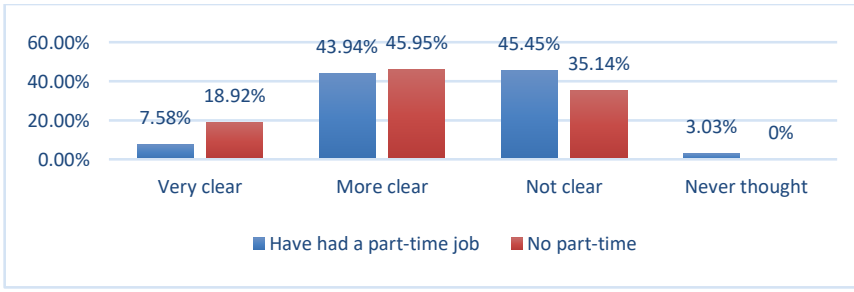

Figure 3-4 Cross-analysis on Part-time Job Experience and Career Planning

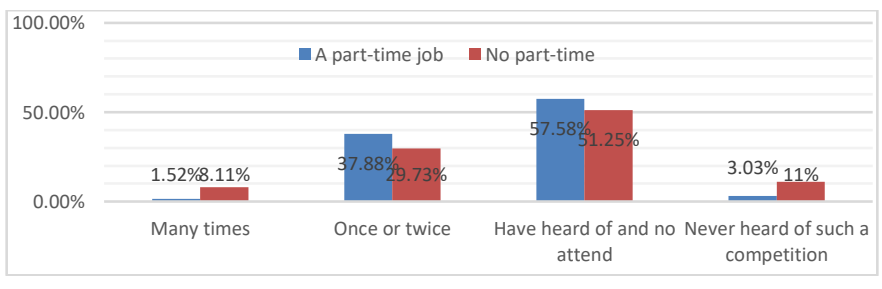

Figure 3-5 Cross-analysis on Part-time Job Experience and Subject Competition 


\subsection{Summary of Survey Analyses}

Through the survey and analysis, we find that the goal of applied technology-based universities is to train more innovative entrepreneurial talents and professional graduate students. In the survey, although current college students have the awareness of practice, their practical experience is not sufficient and even participate in many useless part-time jobs.

The main purpose of VBSE training platform is to simulate business social companies and positions through computer platform, and use relevant management theories learned in the first and second grade to conduct practical operation in the virtual environment platform, so that students can understand various operation steps of the company in advance, and in addition to get familiar with relevant business processes, they can also combine the theory with practice to verify the fitting degree between the logic concept generated in the theoretical learning and the reality, to truly achieve "learning for practice, and practicing for learning", and to cultivate practical staff with high potential and global view.

Therefore, after a series of cross-analyses, I believe that, first of all, conducting VBSE course training on economic management students in the school can help students of the School of Economics and Management conduct professional practice. Compared to blindly participating in parttime activities in the community, it has more benefits for career planning development. Second, it can be seen from another reflection that students actively participating in innovation and entrepreneurship competition in the school are relatively more supportive for the VBSE courses, which reflects that VBSE courses stimulate students' enthusiasm for innovation and entrepreneurship in Wuhan Donghu University.

\section{Talent Training Reform and Innovation Based on VBSE Training Platform}

\subsection{Adapting to the Trend of the Times, and Paying Attention to the Personality Development of Students}

With the economic development, the living standard is increasing day by day. Contemporary college students pay more attention to self-demand and personality development. Especially for innovative talents, more attention should be paid to personalized training. It is necessary to focus on guiding and stimulating, combined with practical operation, which means in the teaching process teachers can combine basic knowledge with students' interest, and take heuristic, guided teaching methods, to cultivate the interests of college students.

In VBSE class, teachers change from a leader into an assistant, just control the platform and help students understand the rules, and the operation and simulation development of all the companies depend on the students' own team choice. But when students encounter difficulties, teachers should timely assist to stimulate students' interest and thinking. Compared with the traditional "spoon-fed" teaching, it can better stimulate students' potential.

\subsection{Meeting Social Needs, and Cultivating Innovative Practical Ability}

Modern enterprises need complex talents and also have different requirements for students based on different positions - research, application, etc., so that students should enhance their own overall quality besides learning professional knowledge. School education should consider the development goals of students, and develop appropriate training methods to meet social needs, to promote the comprehensive development of students, so as to increase the competitiveness of students and reduce the initial adaptive phase of society.

In VBSE courses, students not simply study the operation of the company and job settings, and students' own quality can also be reflected. For example, in the simulation, the first part of "company culture construction" has CEO campaign speech, team building ideas, staff recruitment design, recruitment posters, recruitment promotion and other simulations, which requires students to produce specialized PPT materials for class lectures. Subsequently, team management, internal staff collaboration issues, external communication and negotiation between different companies, enhance the overall quality of students in varying degrees. In the survey, 95\% of students in Wuhan Donghu University hope to add practical knowledge to the courses.

\subsection{Optimizing the Curriculum Structure, and Building Training Base}

With the development of economy, more and more science and technology are applied into education. In 2015, NPC\&CPPCC put forward "Internet+" concept, and then "Internet + education" "micro-class" and "MOOC" model are quickly applied into higher education. And now VBSE development would also be a combination of computer software and education. The common feature of these new developments is to use the latest technology to change the traditional model of "teachers speak and students listen". "Flipped classroom" broadens students' knowledge, combined with relevant actual practical knowledge, so that students can better study and use knowledge.

In addition to the use of high technology, institutions of higher learning should also change the training system, and set corresponding practice credits besides the credit mechanism of theoretical knowledge. For example, Wuhan Donghu University focuses on training applied talents, second grade mainly studies theoretical knowledge, VBSE courses are set in the third grade to connect with social practice, and training special talents and constructing special training base are also good ways. Although students have different choices for the future, training innovative talents is in line with the trend of social development. Specialized training base is established, and relevant technology is used to stimulate students' enthusiasm and interest in learning. Specialized teaching laboratories are established under related business incubation base and VBSE training platform, to provide teachers to guide students and to enable students to increase innovation and entrepreneurship ability.

\section{Conclusion}

VBSE courses break through the imprisonment of traditional teaching which not only guides students to combine theory with practice, but also encourages sharing and innovation. In the simulation training process, person in charge of the post shares experience and guides others to optimize the business. At the same time, VBSE training platform is applied for practice on the basis of laying a good foundation. On the basis of theoretical knowledge, supplemented by VBSE practice courses, and combined with the comprehensive use of the practice outside the school, the core competitiveness of applied undergraduate and applied talents can be increased. At this stage, both research universities and applied universities, in the new form, need to use the new technology to reform and innovate, new ideas should be applied, and new technologies should be learned, to cultivate talents who can contribute to social development and have higher overall quality, abundant professional knowledge, perfect practical skills and global awareness.

\section{Acknowledgement}

This work was supported by the grants from the teaching project of Wuhan Donghu University [2016] and the project number is 160013.The title is: Study on the Innovative Talents Training Mode of College Students Based on VBSE Training Platform-- A Case Study of Wuhan Donghu University.

\section{References}

[1] Wang Xiaohui. Study on the Training Mode of Individualized Talents in First-class Universities. Doctor's Degree of Huazhong Normal University [D]. 2014.182-189.

[2] Tu Juanjuan. Study on the Training of Undergraduate Innovative Talents in High-level Universities in China[D]. Master's Degree of Wuhan University of Technology. 2009:50-54.

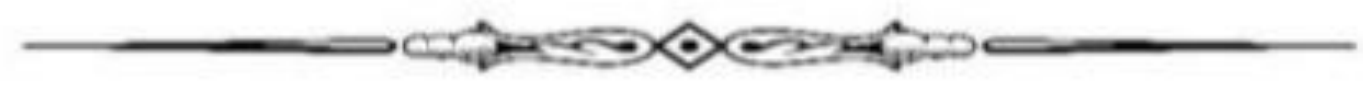

